This item was submitted to Loughborough's Research Repository by the author.

Items in Figshare are protected by copyright, with all rights reserved, unless otherwise indicated.

\title{
Multilevel optimization of composite panels under complex load and boundary conditions
}

PLEASE CITE THE PUBLISHED VERSION

http://dx.doi.org/10.1007/s00158-007-0181-8

\section{PUBLISHER}

(c) Springer-Verlag

VERSION

SMUR (Submitted Manuscript Under Review)

\section{PUBLISHER STATEMENT}

This work is made available according to the conditions of the Creative Commons Attribution-NonCommercialNoDerivatives 4.0 International (CC BY-NC-ND 4.0) licence. Full details of this licence are available at: https://creativecommons.org/licenses/by-nc-nd/4.0/

\section{LICENCE}

CC BY-NC-ND 4.0

\section{REPOSITORY RECORD}

Featherston, Carol A., and Andrew Watson. 2015. "Multilevel Optimization of Composite Panels Under Complex Load and Boundary Conditions". figshare. https://hdl.handle.net/2134/17935. 


\title{
Multilevel Optimisation of Composite Plates and Panel Under Complex Load and Boundary Conditions
}

\author{
C A Featherston $\dagger^{*}$ and A Watson $\ddagger$ \\ †Cardiff School of Engineering, Cardiff University, Queen's Buildings, PO Box 925, Cardiff, \\ CF24 0YF, UK \\ $\ddagger$ Department of Aeronautical and Automotive Engineering, Loughborough University, \\ Loughborough, LE11 3TU, UK
}

\begin{abstract}
Due to their complexity and therefore large numbers of design variables, aerospace structures, such as aircraft wings, are best optimised using a multilevel process. In addition to simplifying the optimisation process, such methods allow a combination of different methods to be used as appropriate, again increasing the efficiency of the analysis.
\end{abstract}

This paper presents a technique based on a combining finite element analysis, which whilst allowing accurate models of structures with complex geometries to be created is computationally expensive and therefore time consuming with a more specialist software, the 'exact' strip program VICONOPT, which provides fast, efficient solutions for a limited number of geometries and loading conditions.

The underlying principles of the optimization procedure are demonstrated by optimising a series of flat plates and curved panels under combined shear and in-plane bending, a load case commonly found for example in aircraft wing spars.

Keywords Carbon fibres, Buckling, Finite element analysis (FEA), Finite strip, Optimisation.
NOTATION
B coupled in-plane and flexural stiffness sub matrix for a plate
D flexural stiffness sub-matrix for a plate

* Corresponding author, tel +44(0)2920 875328, fax +44(0)2920 874317, email FeatherstonCA@cardiff.ac.uk 


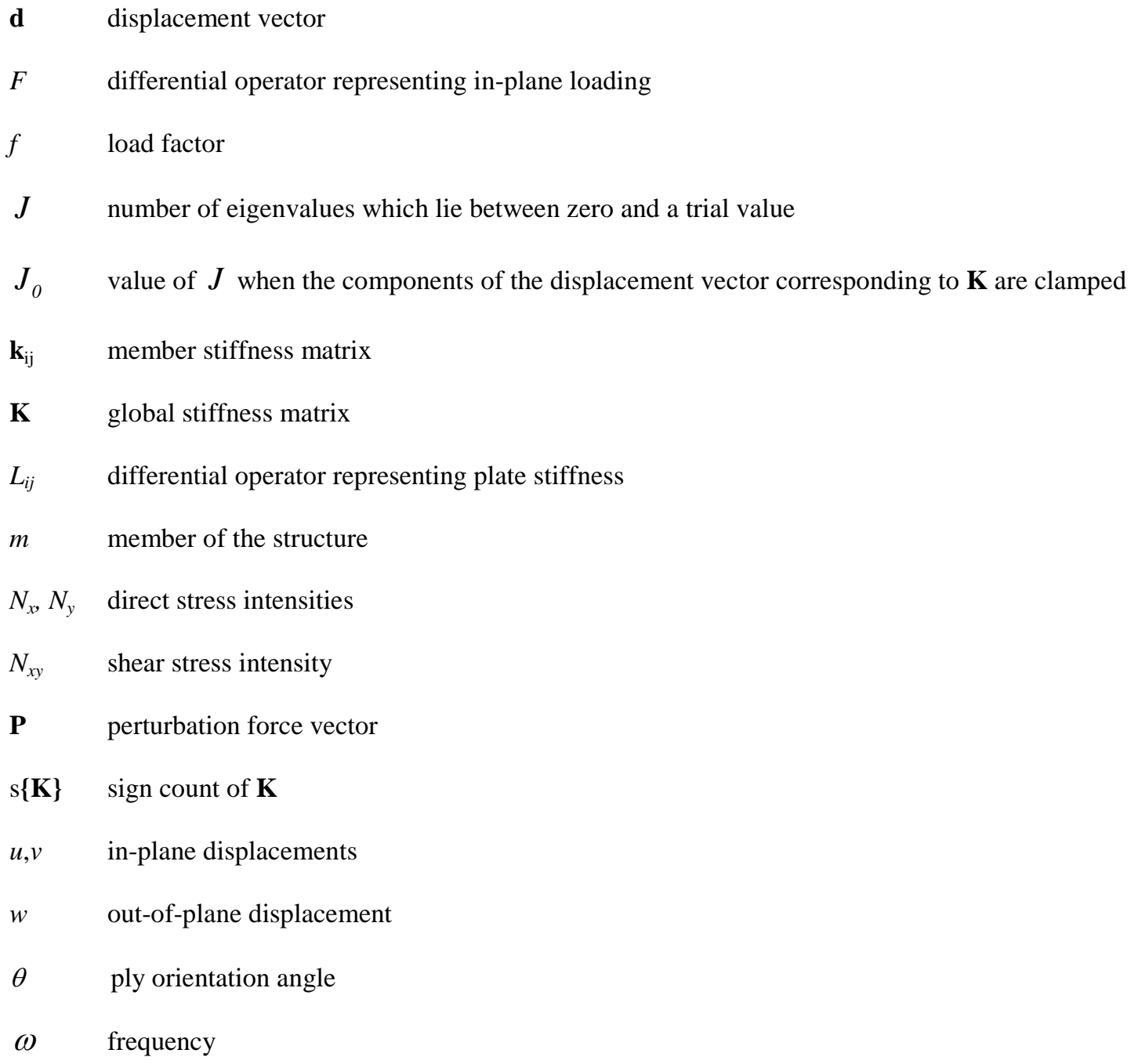

\section{$1 \quad$ Introduction}

The design and optimization of aerospace structures is a complex task. The structural configuration, combined with the wide range of loading and boundary conditions experienced, leads to the need for a multilevel optimization approach. During the 1990s, research into the optimization of aerospace structures was carried out by the Group for Aeronautical Research and Technology in Europe (GARTEUR), which recommended the development of multidisciplinary and multilevel design techniques.

This is by no means a trivial task. While the widely used finite element analysis (FEA) is very versatile, allowing structures with a wide range of loading and boundary conditions to 
be analyzed, it comes at a high computational cost. This is particularly the case when performing design optimization involving large numbers of design variables, which requires many finite element analyses to be carried out.

The specialist analysis and optimum design software $\mathrm{VICON}^{2}$ is based on an 'exact' strip method, and so allows prismatic aerospace structural components, such as aircraft wing panels, to be analyzed in a much faster and more efficient way. However, while the software can analyze and design integral structural components whose cross-sections and loading are longitudinally invariant, it is unable to design a general 3-dimensional structure subject to a complex external loading. Typically, finite element analyses of the overall structural system are required to determine the loads acting on the individual structural components prior to any VICON analysis and optimization. Despite this and some approximations required by the modeling process, VICON has been used for analysis and design purposes, in both industry and academia, for more than a decade.

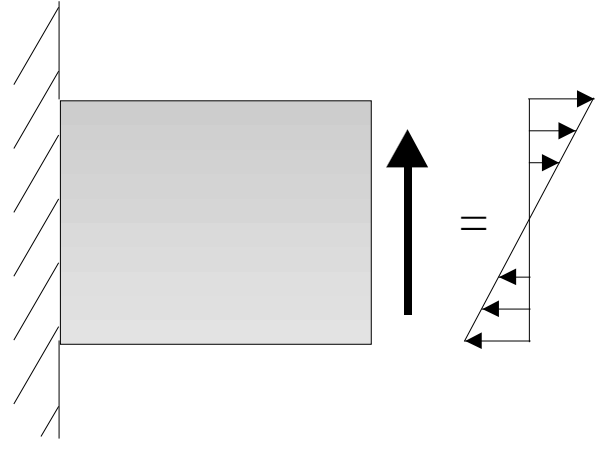

End load

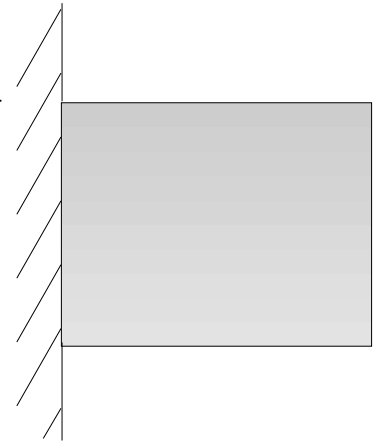

In-plane bending

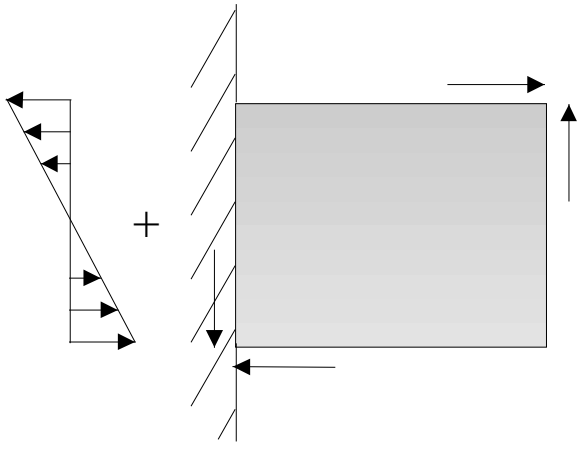

Shear

Figure 1 Load case

This paper presents the results of a study which combines both of these techniques using a multilevel approach, in order to optimize the lay-up of a series of flat plates and curved panels built-in at one end and loaded in shear across the other to create a complex 
combination of shear and in-plane bending which varies throughout the structure, typical of that found in an aircraft wing spar (Figure 1).

Three different geometries of plate and nine panels with different aspect ratios and radii of curvature were examined. Each plate/panel was constructed from eight plies of carbon fibre epoxy pre-preg arranged in a balanced, symmetrical lay-up. In each case the lay-up was designed to optimise the buckling strength using a combination of VICON and the commercially available finite element analysis (FEA) code ABAQUS/Standard.

\section{Optimisation}

\subsection{Method}

In order to determine the optimum design for each of the plates and panels, a two-stage process was undertaken.

In the first stage, the software VICON was used to perform series of parametric studies on a model with simplified geometry, load and boundary conditions. In each of these studies the effect of varying ply orientation on the buckling load was investigated by altering the lay-up of each ply in five degree steps, whilst maintaining a balanced symmetric lay-up. Due to the efficiency of the analysis, it was possible to a large number of studies relatively quickly, thereby generating response surfaces plotting buckling load against lay-up for each geometry, from which an optimum design to this simplified problem could be selected.

Following this initial optimisation, the finite element analysis software ABAQUS/Standard was used in combination with a more accurate model in terms of geometry load and boundary 
conditions to perform a second study using a linear eigenvalue analysis based around the optima determined in the first stage using VICON.

In this way each piece of software was used to its best effect, with the majority of analyses being carried out using the extremely efficient VICON, and the final solution determined using FEA.

\section{$2.2 \quad$ VICON}

VICON [1] is a panel analysis computer program, which incorporates the earlier program VIPASA (Vibration and Instability of Plate Assemblies including Shear and Anisotropy) [2] but includes more complex constraints (VIpasa with CONstraints). VICON covers elastic buckling, postbuckling and free vibration of prismatic plate assemblies, and provides an efficient design tool when buckling is a concern. In contrast to conventional finite element methods, the analysis uses a transcendental stiffness matrix derived from an analytical or numerical solution of the governing differential equations of the component plates. For any longitudinally invariant loading combination (of longitudinal, transverse, in-plane shear and pressure loads), critical buckling loads, undamped natural frequencies and mode shapes can be found with certainty, using procedures based on the Wittrick-Williams algorithm [3].

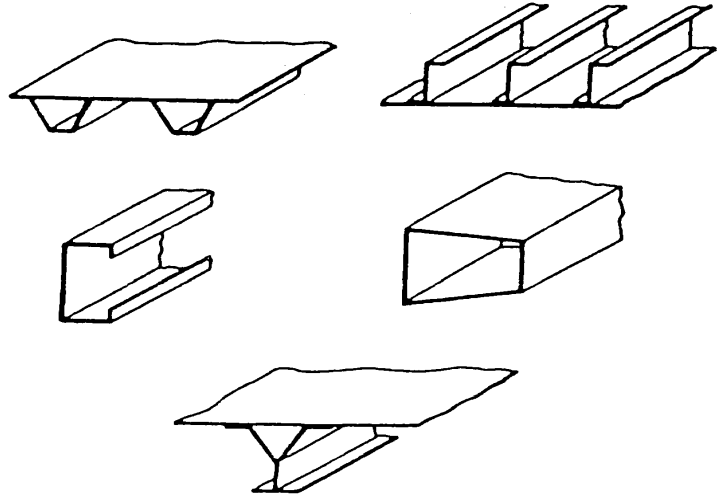

Figure 2 Typical sections which VICON can analyze 


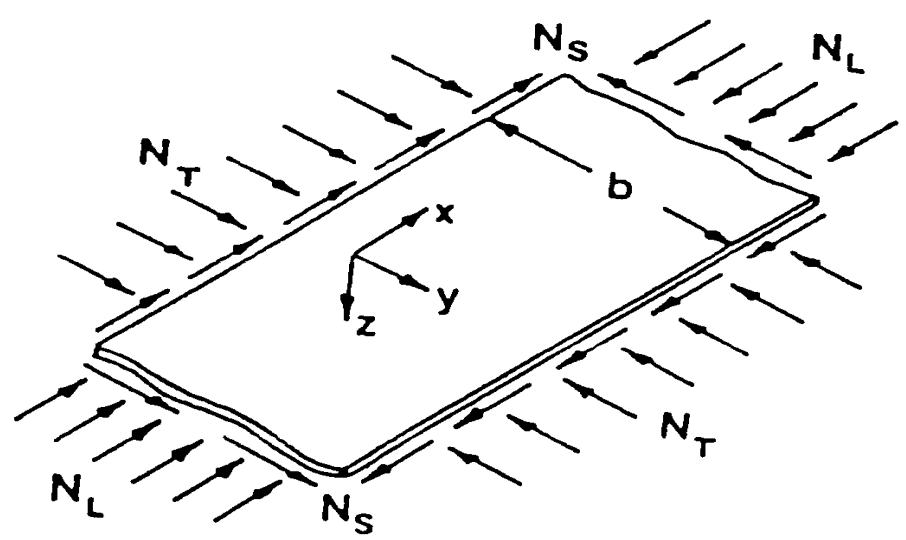

Figure 3 Component plate with in-plane loading

In the original form of the software VIPASA, the modes of buckling or vibration are assumed to have a sinusoidal longitudinal variation with half-wavelength $\lambda$, limiting the load cases which can be considered. In VICON the assumed modes are sums of VIPASA modes, obtained by coupling different values of $\lambda$ thereby extending the original capability to allow end conditions to be modeled more accurately for overall modes of plate assemblies with substantial in-plane shear loads, for which VIPASA gives very conservative results. Typical sections which VICON can analyse, and a typical component plate showing in-plane loading are given in Figures 2 and 3.

\section{'Exact' Strip Method and Wittrick-Williams Algorithm}

As stated previously VICON analyses are based on an 'exact' finite strip method which assumes a continuous distribution of stiffness over the structure rather than discretized stiffnesses at nodal points, as is the case for the more widely used finite element method. The exact strip method is based on solutions to the partial differential equations, which govern the in-plane and out-of-plane deformation of the component plates. Where possible, an analytical solution procedure [2] is used to determine the member stiffness matrices $\mathbf{k}_{i j}$, which are subsequently assembled into the global stiffness matrix $\mathbf{K}$ for the overall structure. If an 
analytic solution of the member equations is not available the $\mathbf{k}_{i j}$ matrices can be found by solving the member equations numerically [4]. The global stiffness matrix $\mathbf{K}$ relates a finite set of displacements $\mathbf{d}$ at the nodes of the structure to their corresponding perturbation forces $\mathbf{P}$, by

$$
\mathbf{K d}=\mathbf{P}
$$

The critical buckling load factors or natural frequencies of the structure correspond to the eigenvalues found by solving

$$
\mathbf{K d}=\mathbf{0}
$$

where $\mathbf{K}$ consists of transcendental, and thus highly non-linear, functions of the load factor $f$ or frequency $\omega$ [5]. The solution of this transcendental eigenvalue problem requires an iterative search for values of $f$ or $\omega$ at which Eq. (3) is satisfied. VICON makes use of the Wittrick-Williams algorithm [5,6], which allows eigenvalues (i.e. critical buckling load factors or natural frequencies of free vibration) to be found with absolute certainty. The algorithm calculates $J$, the number eigenvalues, which lie between zero and any trial value of $F$ or $\omega$. Any change in $J$ between two trial values is equal to the number of eigenvalues lying between these trial values.

In its general form the Wittrick-Williams algorithm can be stated as

$$
J=J_{0}+\mathrm{s}\{\mathbf{K}\}
$$

where $s\{\mathbf{K}\}$ is known as the sign count of $\mathbf{K}$, and is equal to the number of negative leading diagonal elements of the upper triangular matrix $\mathbf{K}^{\Delta}$ obtained by applying conventional Gauss elimination, without pivoting, to the matrix $\mathbf{K} . J_{0}$ is the value $J$ would have if all the 
freedoms corresponding to $\mathbf{K}$ were clamped. Unless substructures are used, $J_{0}$ can be calculated as

$$
J_{0}=\sum_{m} J_{m}
$$

where the summation is over all members $m$ of the structure, and $J_{m}$ is calculated for each member as the number of critical load factors or natural frequencies exceeded by the trial value, when the member ends are clamped.

\subsection{Finite Element Analysis}

The second part of each analysis was carried out using classical eigenvalue buckling analysis in the commercially available finite element analysis software ABAQUS Standard. ABAQUS performs buckling analyses using a linear perturbation procedure. First the stiffness matrix at a state corresponding to the base state loading on the structure is stored and then a small perturbation or live load is applied. In the cases modelled the base state is the unloaded condition and the matrix used is the original stiffness matrix. The program then derives the initial stress matrix due to the live load and an eigenvalue calculation is performed to determine a multiplier to the live load at which the structure becomes unstable. Thus the buckling load can be calculated.

\section{$3 \quad$ Examples}

The technique was applied to two different geometries of specimen, a flat plate and a curved panel, loaded under combined shear and in-plane bending. In each case, the two stage optimization process described above was used to determine the optimum solution in terms of the specimen with the highest buckling load for the given number of plies. 


\subsection{Flat Plate Under Combined Shear and In-Plane Bending}

\section{Background}

The application of classical thin plate buckling theory to laminated composite plates leads to a set of three eighth order coupled partial differential equations (7) (Niu [7]) (the increased complexity from the homogeneous shell problem, in which coupling between inextensional and membrane theories can be considered negligible for small deflections, is caused by the inherent coupling due to unsymmetric lamination):

$$
\left[\begin{array}{ccc}
L_{11} & L_{12} & L_{13} \\
L_{21} & L_{22} & L_{23} \\
L_{31} & L_{32} & (L-F)
\end{array}\right]\left\{\begin{array}{l}
u \\
v \\
w
\end{array}\right\}=\left\{\begin{array}{l}
0 \\
0 \\
0
\end{array}\right\}
$$

where $L_{i j}$ are differential operators representing the plate stiffness, and $F$ is a differential operator representing the in-plane loading.

For symmetrically laminated plates, , the $B$ stiffness coefficients become zero. This allows the in-plane part of the problem to be uncoupled from the transverse part. The in-plane part then yields $u=v=0$ in the buckled configuration and the transverse displacements are governed by a fourth order partial differential equation, which is in a similar form to the buckling equation for a homogenous anisotropic plate.

$$
\begin{aligned}
& D_{11} \frac{d^{4} w}{d x^{4}}+4 D_{16} \frac{d^{4} w}{d x^{3} d y}+2\left(D_{12}+2 D_{66}\right) \frac{d^{4} w}{d x^{2} d y^{2}}+4 D_{26} \frac{d^{4} w}{d x d y}+D_{22} \frac{d^{4} w}{d y^{4}} \\
& =N_{x} \frac{d^{2} w}{d x^{2}}+2 N_{x y} \frac{d^{2} w}{d x d y}+N_{y} \frac{d^{2} w}{d y^{2}}
\end{aligned}
$$

In most cases it is not possible to find an exact closed form solution to the differential equations for a composite plate although some can be solved using approximate numerical 
techniques such as energy methods, with an assumed single or double trigonometric infinite series which also satisfies the required boundary conditions being used to represent the deflected shape of the mid-surface of the plate.

For the particular case of interest, a plate under combined shear and in-plane bending with two long edges simply supported and two short edges clamped, basic design guides (Niu [7]) suggest that optimisation of the lay-up to maximise the initial buckling load for a plate of a specific thickness provides two possibilities: a plate formed from a combination of $\pm 45^{\circ}$ plies on the outer surfaces (with the outermost ply orientated such that it will be in compression) to increase shear strength and $90^{\circ}$ plies towards the mid-plane to provide strength under compression, or a symmetrical angle ply plate in which the optimum angle varies with the aspect ratio of the plate. Both lay-ups result in symmetric but anisotropic plates with non zero values for $D_{16}$ and $D_{26}$, which require solutions to be found to equation (2) above.

For the second case of a symmetrical angle ply plate Jones [8] found that $D_{16}$ and $D_{26}$ are large for small numbers of plies and become smaller relative to the other coefficients as the number of plies is increased. For an angle ply plate with a large, odd number of plies therefore, these coefficients may be quite small and their effect minimal. However, even then, they cause the results to vary from those cases in which they are zero, and cannot therefore be ignored to simplify the theory. In addition to this, in the specimens it is aimed to manufacture, the number of plies is relatively small and thus $D_{16}$ and $D_{26}$ will still be large with respect to the other coefficients.

The inclusion of the $D_{16}$ and $D_{26}$ terms in the governing equation makes the exact solution of the problem for plates of finite dimensions impossible. Study of such problems therefore 
requires the application of techniques such as those used here namely VICON and finite element analysis.

\section{VICON Analysis}

As discussed earlier, for each of the plates being examined, a series of VICON analyses were performed to create response surfaces representing the variation of buckling load with lay-up. Each of the models used was constructed from 10 strips. The plate was clamped along its loaded edges by restricting out-of-plane displacement and rotation. In order to speed up the process due to the large number of analyses required, this was achieved using a small number of point supports and a small number of wavelengths to represent the mode (Watson et al [9]). The remaining edges were simply supported by restricting out-of-plane displacement. A shear load was applied to the ends of each of the strips, and in-plane bending was modelled by applying a series of compressive and tensile loads, which varied linearly from the top to the bottom edge of the plate. In each case the lay-up was assumed to be symmetric and balanced to minimise the possible alternatives. Individual plies were then paired such that each pair had one ply at $+\theta$ and one at - $\theta$ (where $\theta$ is defined as illustrated in Figure 4).

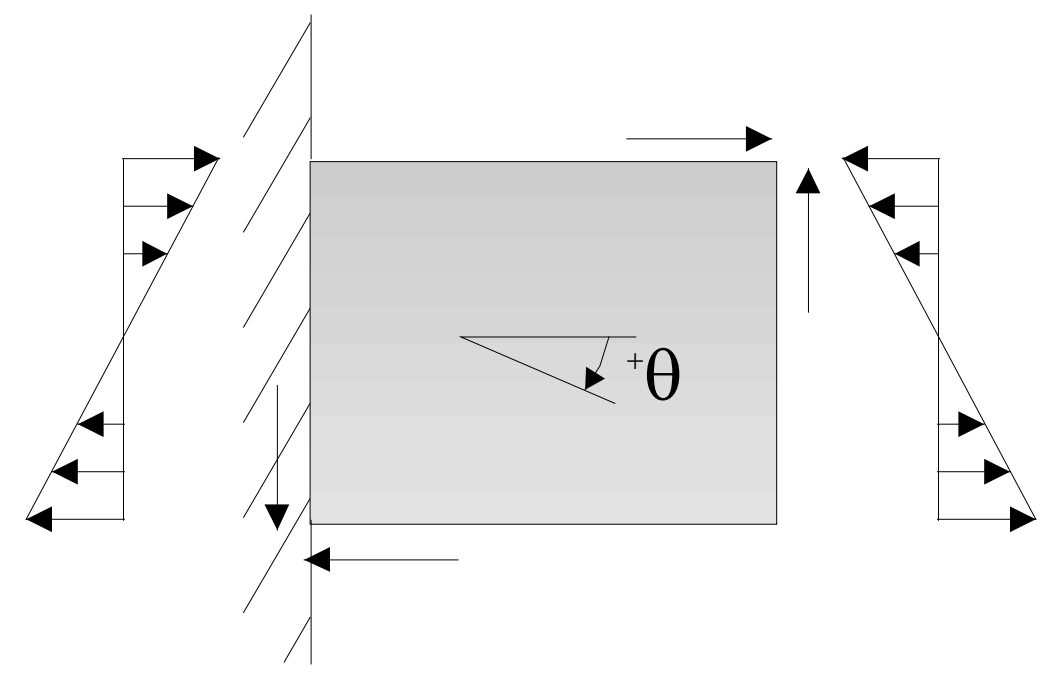

Figure 4 Ply orientation 
As in each case the laminate comprised eight plies three possible combinations of pairs existed; plies 1 and 2 and plies 3 and 4; plies 1 and 3 and plies 2 and 4; and plies 1 and 4 and plies 2 and 3, and three response surfaces were therefore generated for each aspect ratio of plate. The angle of each pair was varied in steps of $\pm 5^{\circ}$, thereby producing 1369 results for each response surface. Using a 333MhZ Sun Ultra 10 computer, these results took 342 seconds to generate for each surface illustrating the efficiency of the programme.

\section{FEA Analysis}

Once the optimum lay-up based on the VICON analyses had been determined, a small number of finite element analyses where performed in the region of this design (again by varying the ply angle by $\pm 5^{\circ}$ ) to identify the optimum angle ply based on an exact representation of the test undertaken (since the VICON analyses had been based on a number of assumptions which changed the loading and boundary conditions of the plates being analysed slightly relative to those being tested, such as the application of pure shear where in the test shear varies across the panel, and the application of a fixed bending load when in the test the bending load varies with the moment arm and therefore is maximum at the built-in end and zero at the end of load application). In this particular example, the design of the plate was in each case limited to an angle ply which further reduced the number of analyses necessary.

The finite element mesh for each plate modelled was constructed from $5 \mathrm{~mm}$ x $5 \mathrm{~mm}$ shell elements. The elements used were the quadrilateral elements S8R5, which behave in a manner consistent with thin shell theory. These are eight noded elements, which utilize quadratic equations to describe the behaviour of each edge. Following calculation of the displacement at each node, stresses and strains are determined at four integration points 
(instead of the standard eight) and then extrapolated to give the values at each node. The nodes have five degrees of freedom, three displacements and two in surface rotations.

The boundary conditions used for each model can be described by reference to Figure 5 . The first three degrees of freedom represent displacements and the last three, rotations. Edge 1 of the plate was restricted in all six degrees of freedom to model a clamped end condition. Outof-plane displacement 3 and rotation 5 along edges 2 and 3 were prevented to represent simple support. Edge 4 was prevented from moving in 3 and rotations 4 and 5 were restricted. Load was applied using a beam attached to the plate to one end of which shear was applied vertically upwards. This beam was modelled using $5 \mathrm{~mm}$ long 3 noded quadratic beam elements to ensure consistency with the shell elements.

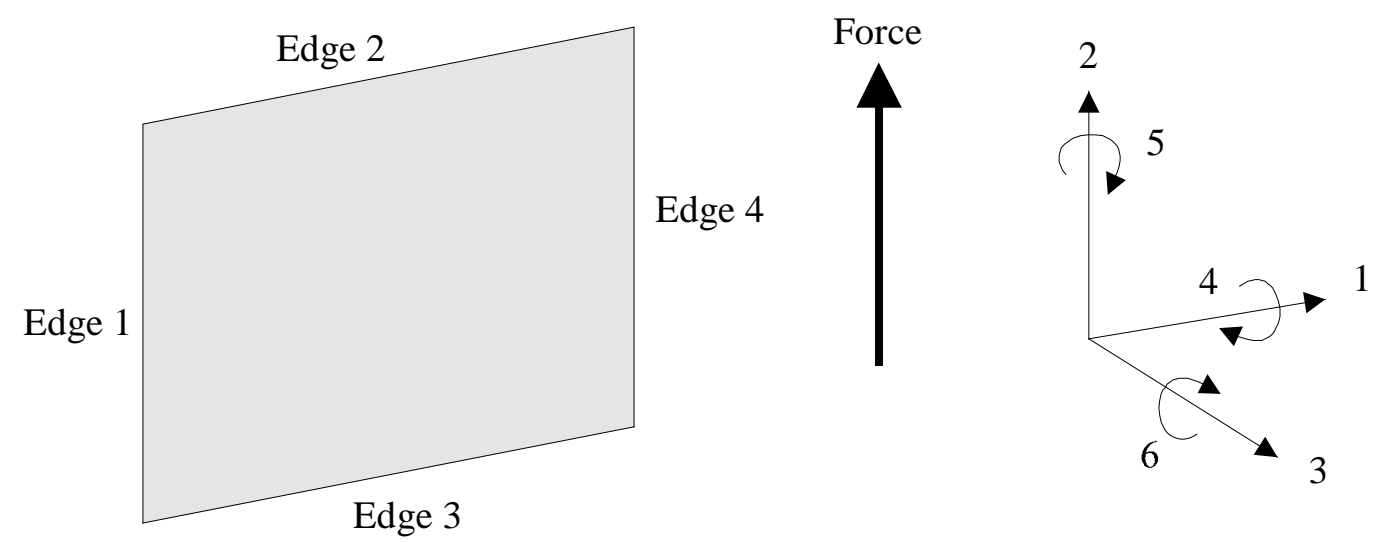

Figure 5 Boundary conditions

\section{Results}

The nine response surfaces generated using VICON analyses are illustrated in Figures 6 to 8 . Study of these surfaces resulted in the optimum lay-ups given in Table 1 being identified. As described above a second procedure using the finite element analysis code ABAQUS/Standard was then undertaken, the results of which are provided in the second column of the table. These final lay-ups then became the ones used during the manufacture of the test specimens. 

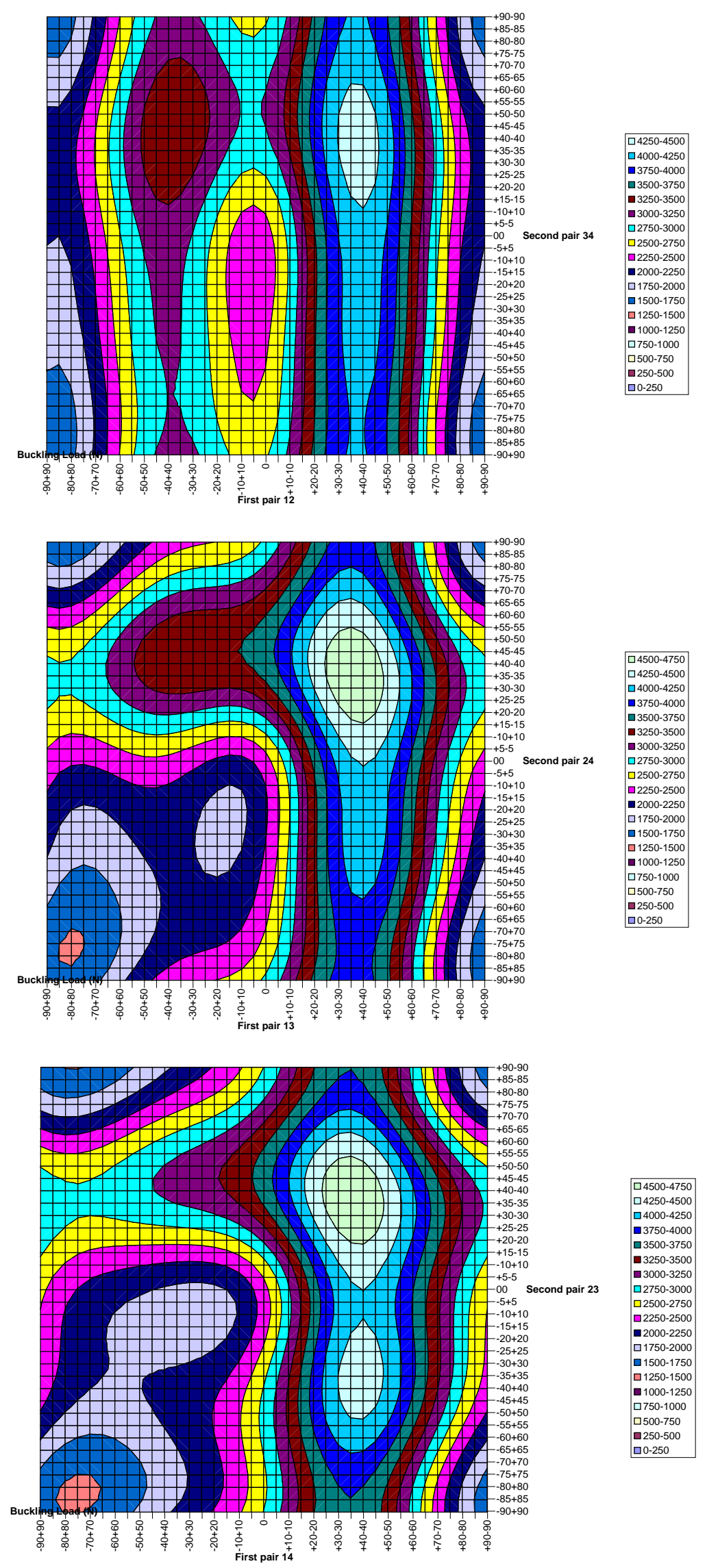

Figure 6 VICON buckling load versus lay-up - aspect ratio 1 


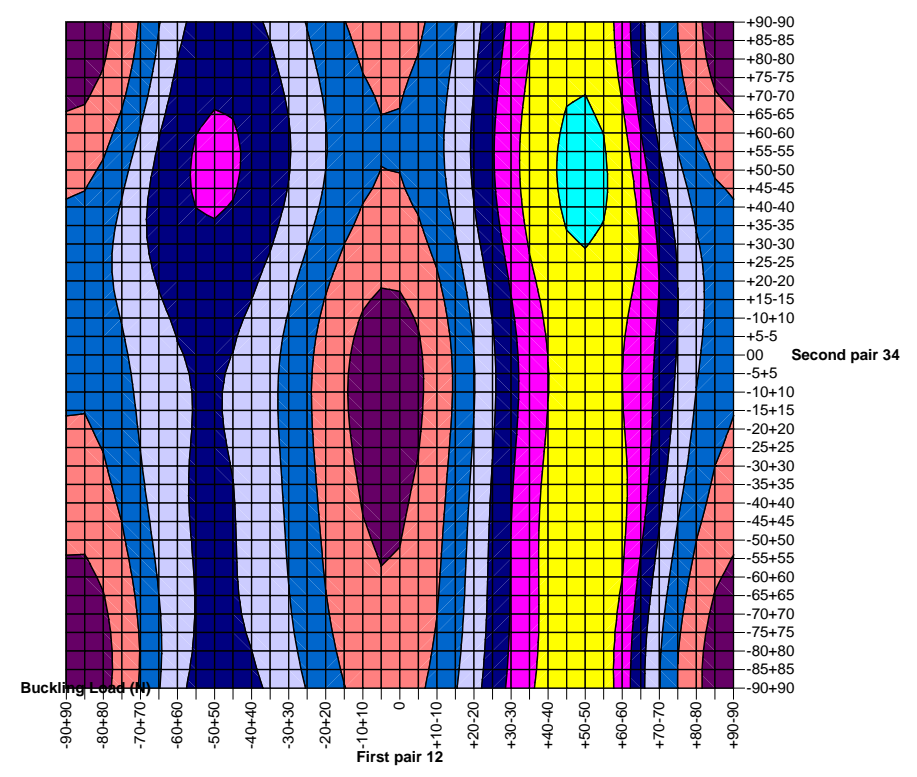

प2750-3000

¿2500-2750

\2250-2500

- $2000-2250$

口1750-2000

—1500-1750

- 1000-1250

$\square 500-750$

Б0-250

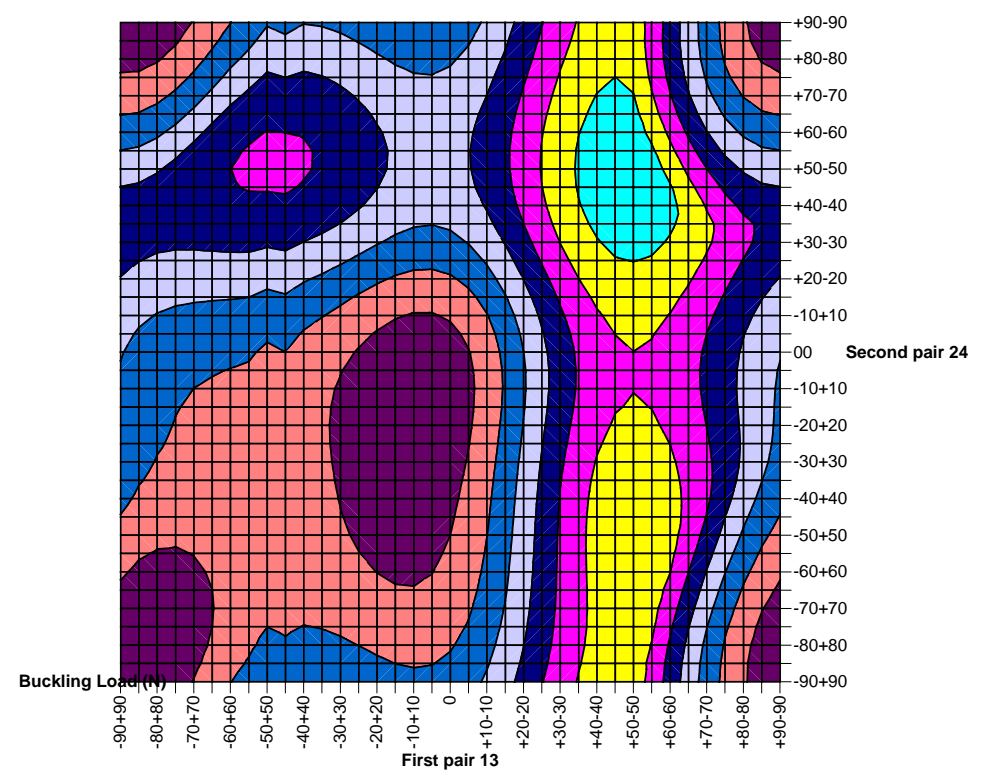

\begin{tabular}{|l|}
\hline$\square 2750-3000$ \\
$\square 2500-2750$ \\
$\square 2250-2500$ \\
$\square 2000-2250$ \\
$\square 1750-2000$ \\
$\square 1500-1750$ \\
$\square 1250-1500$ \\
$\square 1000-1250$ \\
$\square 750-1000$ \\
$\square 500-750$ \\
$\square 250-500$ \\
$\square 0-250$ \\
\hline
\end{tabular}

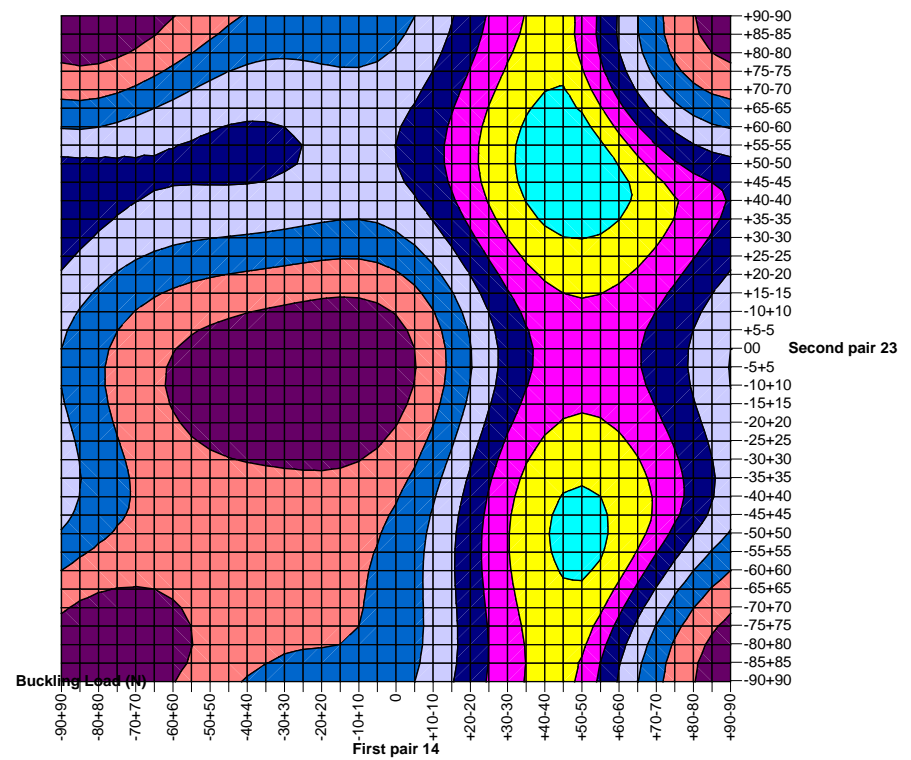

Figure 7 VICON buckling load versus lay-up - aspect ratio 1.5 

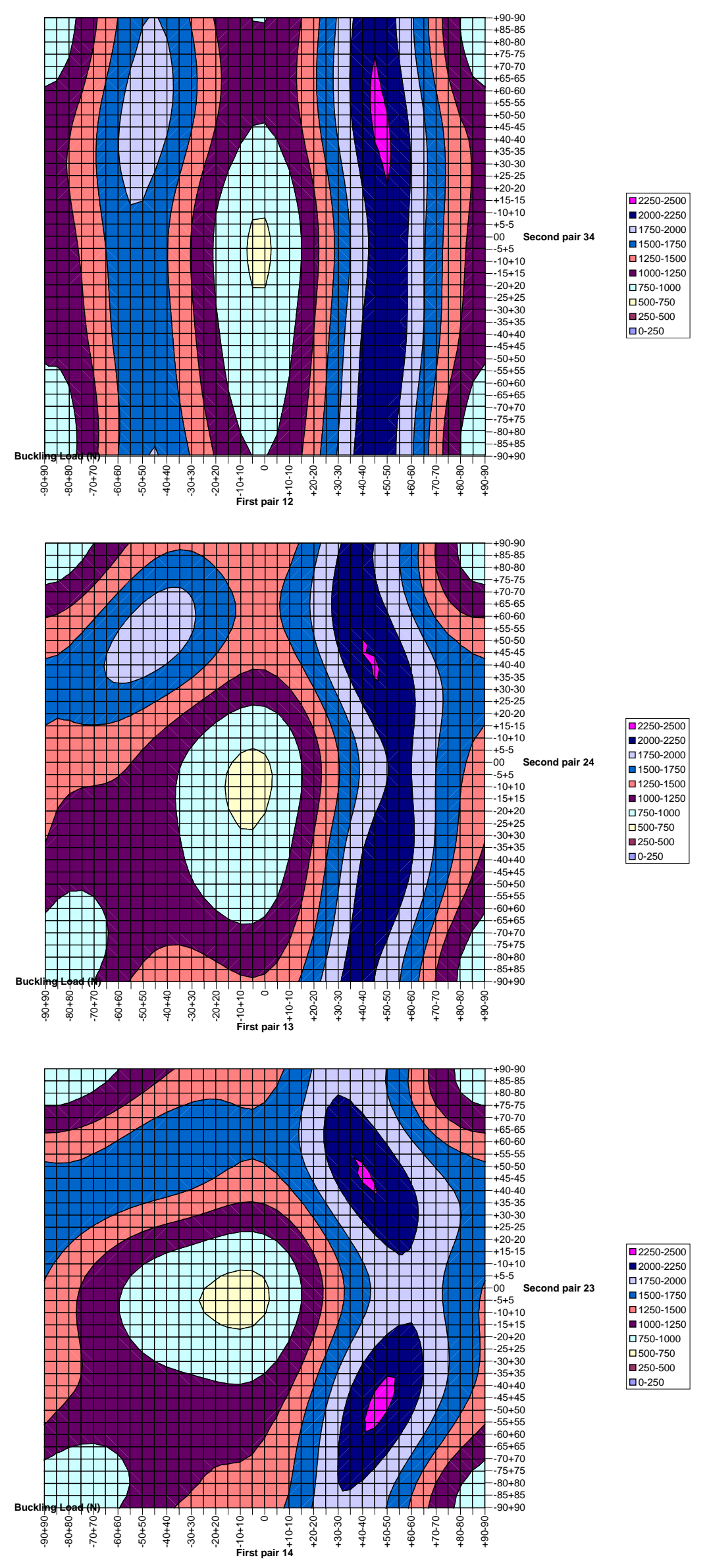

Figure 8 VICON buckling load versus lay-up - aspect ratio 2 


\begin{tabular}{|c|c|c|}
\hline Aspect Ratio & VICON analysis & FE analysis \\
\hline 1 & $(+35 /+35 /-35 /-35)_{\mathrm{s}}$ & $(+25 /-25 /+25 /-25)_{\mathrm{s}}$ \\
\hline 1.5 & $(+50 /+45 /-50 /-45)_{\mathrm{s}}$ & $(+35 /-35 /+35 /-35)_{\mathrm{s}}$ \\
\hline 2 & $(+45 /-50 /+50 /-45)_{\mathrm{s}}$ & $(+40 /-40 /+40 /-40)_{\mathrm{s}}$ \\
\hline
\end{tabular}

Table 1 Optimised lay-ups

\begin{tabular}{|c|c|c|}
\hline Aspect Ratio & $\begin{array}{c}\text { VICON Optimum Buckling } \\
\text { Load (N) }\end{array}$ & Finite Element Analysis (N) \\
\hline 1 & 4699 & 2091 \\
\hline 1.5 & 2913 & 1462 \\
\hline 2 & 2307 & 3710 \\
\hline
\end{tabular}

Table 2 Optimised Buckling Loads

\section{Discussion}

The results of the optimisation performed using VICON presented in the form of response surfaces in Figures 6 to 8 and summarised in Table 1, illustrate that, as the aspect ratio of the plate increases, the optimum ply orientation angle increases. This increase is greater between the 1 and 1.5 aspect ratio plates, than it is between the 1.5 and 2 aspect ratio plates. These effects are confirmed by the results of the finite element analysis, where in fact both are shown more clearly and are also in agreement with the results reported in other studies, where for example for pure shear the ply orientation angle increases as the aspect ratio increases (Chang et al [10] reported that the optimum ply angle for a square plate under shear is as expected $45^{\circ}$ but that this increases to $55^{\circ}$ for plates with aspect ratio 2). Design guides such as Niu [7], which suggest that the ply orientation angle will decrease as the relative proportion of compressive load increases, are also supported, in particular, by examining the difference between the VICON analyses and the FEA results. In the finite element analysis (as in the experiment), the plates are built-in at one end and a load is applied across the other 
introducing shear which varies across the plate and in-plane bending, which increases from zero at the point of load application, to a maximum at the built-in end. As noted earlier, it is not possible to model this varying in-plane bending in VICON since only longitudinally invariant loading can be introduced, so an average load representative of that found halfway along the plate was used. This results in the compressive load in the model being too great at the loaded end of the plate, and too low in the region near the built-in end where the plate buckles. Thus the effects of the compressive loading are underestimated in the most critical region resulting in optimum lay-ups with fibres aligned more towards the transverse direction, than would otherwise be the case. Study of the optimum lay-ups calculated by VICON and FEA show this to be the case, with the finite element results recommending a lay-up in which the fibres are more aligned with the $\theta=0^{\circ}$ direction.

\subsection{Curved Panel Under Combined Shear and In-Plane Bending}

\section{Background}

As is the case for isotropic shells, shell theory for laminated composites is governed by a set of eighth order differential equations whose solution requires four boundary conditions to be defined along each edge of the shell. In composites however, these equations become algebraically more complex than those associated with isotropic shell theory due to the large number of stiffness coefficients involved. In addition to this added complexity, it can also be shown that in contrast to the case of laminated flat plates these equations remain coupled even for midplane symmetric laminates.

Derivation of the shell buckling equations for laminated composite shells is thus a complicated procedure. Depending upon the assumptions made however, (for example the 
use of classical shell theory (CST) or first order shear theory (FST)) various theories can be obtained (Tennyson [11], Leissa [12] and Kapania [13]).

Study of such problems in order to understand and therefore optimise their behaviour therefore again requires the application of techniques such as those used here namely VICON and finite element analysis.

\section{VICON Analysis}

For each of the panels examined, a series of analyses using the VICON route in VICONOPT were performed to create response surfaces representing the variation of buckling load with lay-up.

Each panel was modelled using the curved plate option in VICONOPT. In this option the geometry of the curved panel is approximated by discretising it into a series of flat plate members that are joined to form the complete curved panel. In order to ensure that an adequate number of plate members were used in the analysis a convergence study was undertaken. McGowan and Anderson [14] show a minimum of 100 plate members are necessary for accurately modelling a complete cylinder and the authors found that 50 plate members were sufficient for the panels presented in this paper.

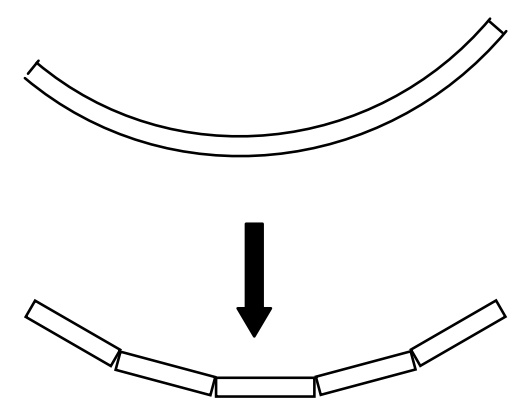

Figure 9 Segmented representation of curved plate geometry used by VICONOPT. 
Each of the models used was constructed from 10 strips. Each strip was modelled as a curved panel made up of five flat plate elements as illustrated in Figure 9.

The panel was clamped along its loaded edges by restricting out-of-plane displacement and rotation. In order to speed up the process due to the large number of analyses required, a small number of point supports were used to represent the line support and a small number of wavelengths were used to represent the mode (Watson et al [9]). The remaining edges were simply supported by restricting out-of-plane displacement.

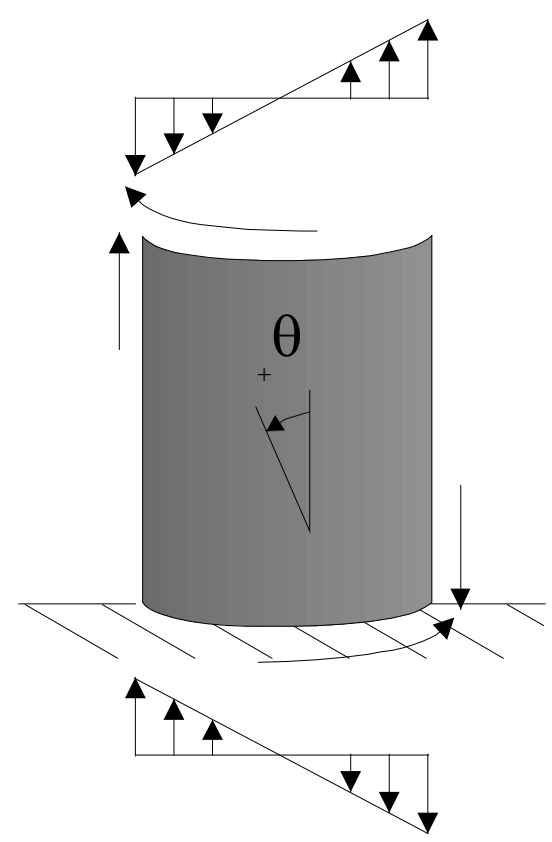

Figure 10 Ply orientation

A shear load was applied to the ends of each of the strips, and in-plane bending was modelled by applying a series of compressive and tensile loads, which varied linearly from the top to the bottom edge of the panel. In each case the lay-up was assumed to be symmetric and balanced to minimise the possible alternatives. Individual plies were then paired such that each pair had one ply at $+\theta$ and one at $-\theta$ (where $\theta$ is defined as illustrated in Figure 10). As in each case the laminate comprised eight plies three possible combinations of pairs existed; plies 1 and 2 and plies 3 and 4; plies 1 and 3 and plies 2 and 4; and plies 1 and 4 and plies 2 and 3, and three response surfaces were therefore generated for each of the nine combinations 
of radius of curvature $(100,177$ and $322 \mathrm{~mm})$ and aspect ratio $(1,1.5,2)$ investigated - a total of 27 response surfaces. The angle of each pair was varied in steps of $\pm 5^{\circ}$, thereby producing 1369 results for each response surface. Using a Pentium 43 GHz 1 GB Ram computer, these results took 253 seconds to generate for each surface demonstrating the efficiency of the programme.

\section{Finite Element Analysis}

Once the optimum lay-up based on the VICON analyses had been determined, a small number of finite element analyses where performed in the region of this design (again by varying the ply angle by $\pm 5^{\circ}$ ) to identify the optimum ply angle based on an exact representation of the test undertaken (since the VICON analyses had been based on a number of assumptions which changed the loading and boundary conditions of the plates being analysed slightly relative to those being tested, such as the application of pure shear, where in the test shear varies across the panel, and the application of a fixed bending load, when in the test the bending load varies with the moment arm and therefore is maximum at the built-in end and zero at the end at which the load is applied).

The panels investigated were modelled using $5 \mathrm{~mm}$ square shell elements for the curved section, and $5 \mathrm{~mm} \times 10 \mathrm{~mm}$ shell elements for the folded over edges, as shown in Figure 11 . The clamps and loading plate were also modelled to ensure accurate load application, using brick elements.

The elements used for the panel were quadrilateral S8R5 elements, which behave in a manner consistent with thin shell theory (i.e. they are based on the Kirchoff-Love theory). These elements are eight noded elements in which edge behaviour is modelled using quadratic equations, which prevent the occurrence of the hourglass effect (in which spurious 
displacements occur perpendicular to the shell surface). Reduced integration, with four integration points instead of the standard eight is used, and each node has five degrees of freedom, namely three displacements and two in-surface rotations.

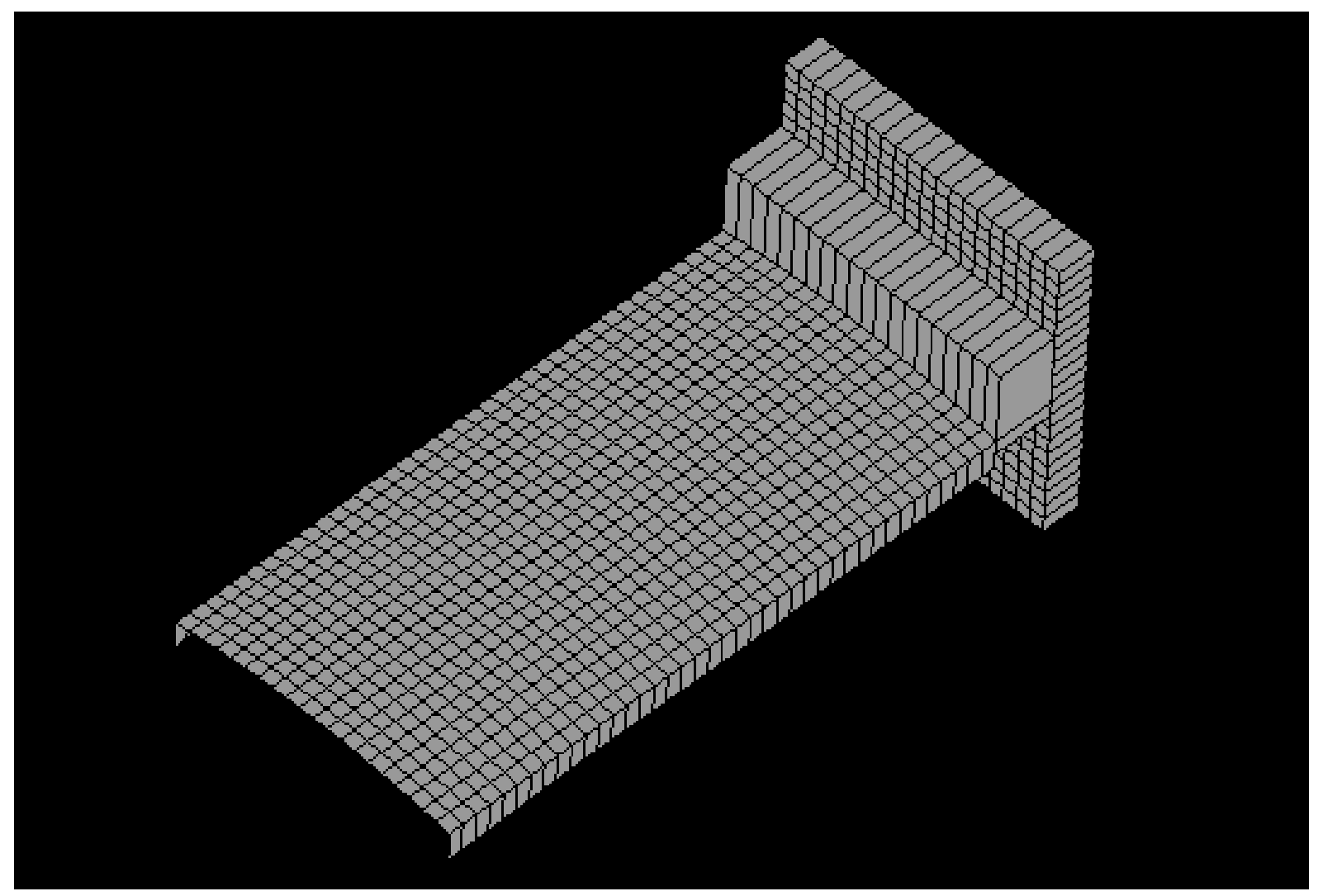

Figure 11 Finite element mesh

The solid elements used to the model the end clamps and loading plate were of type C3D20R.

These are 20 noded elements also with edge behaviour described by quadratic equations.

Nodes have three degrees of freedom (three displacements), and reduced integration is again employed giving 12 integration points. These elements were selected for compatibility with the shell elements.

The boundary conditions applied to the model can be described by reference to Figure 12, with three degrees of freedom representing displacements, and three rotations. Along edge 1, all five degrees of freedom were restrained thus representing the clamped end condition. 
Edges 2 and 3 remained free. Along edge 4, to which the load was applied, boundary conditions were applied to prevent out-of-plane displacement $x$ and rotation about the $y$ axis, but movement and rotation in all other directions were permitted, thus allowing shear and bending to be transmitted through the panel.

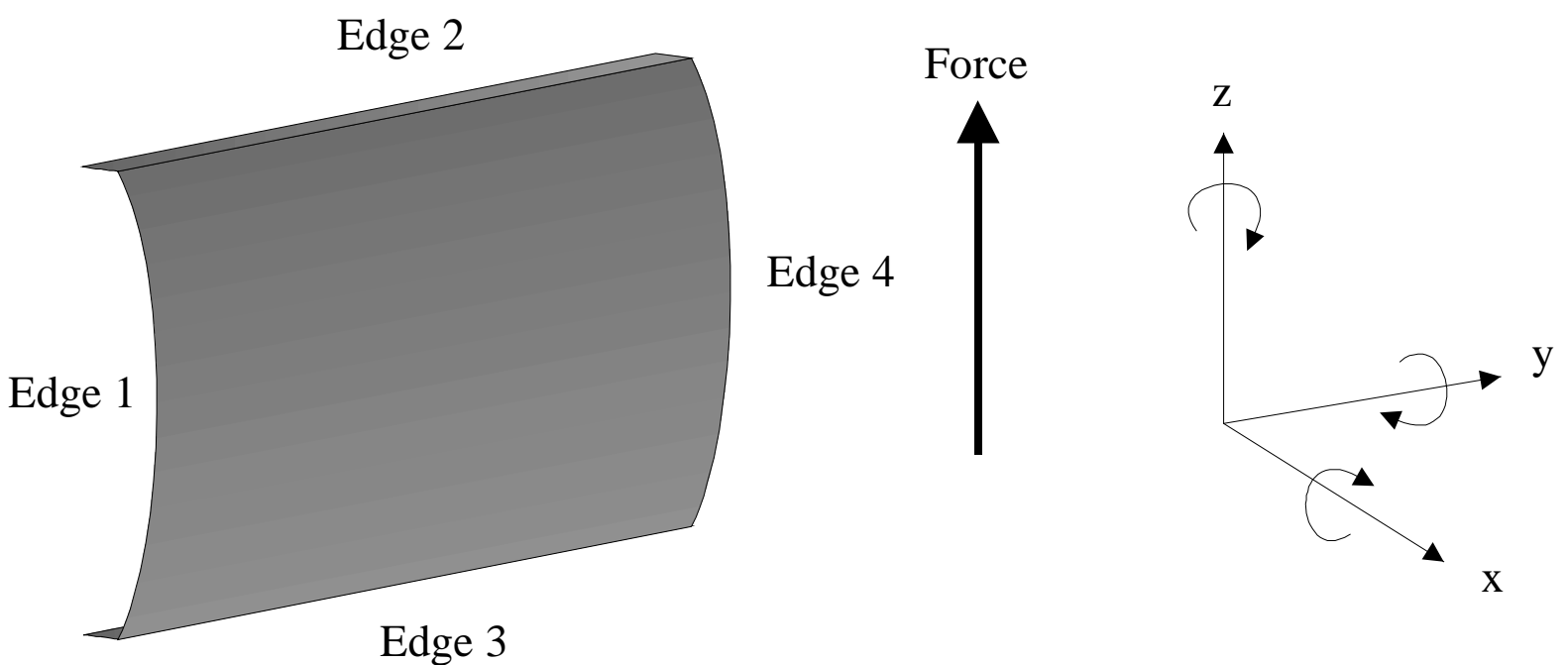

Figure 12 Boundary conditions

\subsection{Results}

A total of 27 response surfaces were generated using the results of the VICON analyses as discussed previously. Study of these surfaces resulted in the optimum lay-ups presented in the third column of Table 3 being identified. As described above, a second procedure using the finite element analysis code ABAQUS/Standard was then undertaken, the results of which are provided in the fourth column of the table.

The results of this second stage of the optimisation procedure are also illustrated in the form of response surfaces in Figures 13, 14 and 15. For each combination of radius of curvature and aspect ratio, the surface illustrated is that obtained by considering plies 1 and 2 and plies 3 and 4 as pairs and varying ply angle accordingly. 


\begin{tabular}{|c|c|c|c|}
\hline Radius of Curvature (mm) & Aspect Ratio & VICON Analysis & FE Analysis \\
\hline 100 & $\begin{array}{l}1 \\
1.5 \\
2\end{array}$ & $\begin{array}{l}(-60 /-30 / 60 / 30)_{\mathrm{s}} \\
(-65 /-30 / 65 / 30)_{\mathrm{s}} \\
(-60 /-30 / 60 / 30)_{\mathrm{s}}\end{array}$ & $\begin{array}{l}(-60 /-20 / 60 / 20)_{\mathrm{s}} \\
(-65 /-20 / 65 / 20)_{\mathrm{s}} \\
(-75 /-30 / 75 / 30)_{\mathrm{s}}\end{array}$ \\
\hline 177 & $\begin{array}{l}1 \\
1.5 \\
2\end{array}$ & $\begin{array}{l}(-60 /-30 / 60 / 30)_{\mathrm{s}} \\
(-60 /-25 / 60 / 25)_{\mathrm{s}} \\
(-65 /-30 / 65 / 30)_{\mathrm{s}}\end{array}$ & $\begin{array}{l}(-65 /-30 / 65 / 30)_{\mathrm{s}} \\
(-65 /-20 / 65 / 20)_{\mathrm{s}} \\
(-65 /-20 / 65 / 20)_{\mathrm{s}}\end{array}$ \\
\hline 322 & $\begin{array}{l}1 \\
1.5 \\
2\end{array}$ & $\begin{array}{l}(-60 /-30 / 60 / 30)_{\mathrm{s}} \\
(-65 /-40 / 65 / 40)_{\mathrm{s}} \\
(-55 /-30 / 55 / 30)_{\mathrm{s}}\end{array}$ & $\begin{array}{l}(-65 /-20 / 65 / 20)_{s} \\
(-60 /-15 / 60 / 15)_{s} \\
(-65 /-20 / 65 / 20)_{s}\end{array}$ \\
\hline
\end{tabular}

Table $3 \quad$ Optimised lay-ups

\begin{tabular}{|c|c|c|c|c|c|c|}
\hline \multirow{2}{*}{ Radius of curvature (mm) } & \multicolumn{2}{|c|}{100} & \multicolumn{2}{|c|}{177} & \multicolumn{2}{c|}{322} \\
\hline \multirow{2}{*}{ Aspect Ratio } & Step 1 - & Step 2 - & Step 1 - & Step 2 - & Step 1 - & Step 2 - \\
& VICON & FE & VICON & FE & VICON & FE \\
& analysis & analysis & analysis & analysis & analysis & analysis \\
\hline 1 & 9945 & 10341 & 7041 & 7149 & 4887 & 5092 \\
\hline 1.5 & 7041 & 7150 & 4771 & 4846 & 3159 & 3465 \\
\hline 2 & 4317 & 5135 & 3765 & 3815 & 2248 & 2552 \\
\hline
\end{tabular}

Table $4 \quad$ Optimised buckling loads 
Aspect ratio 1

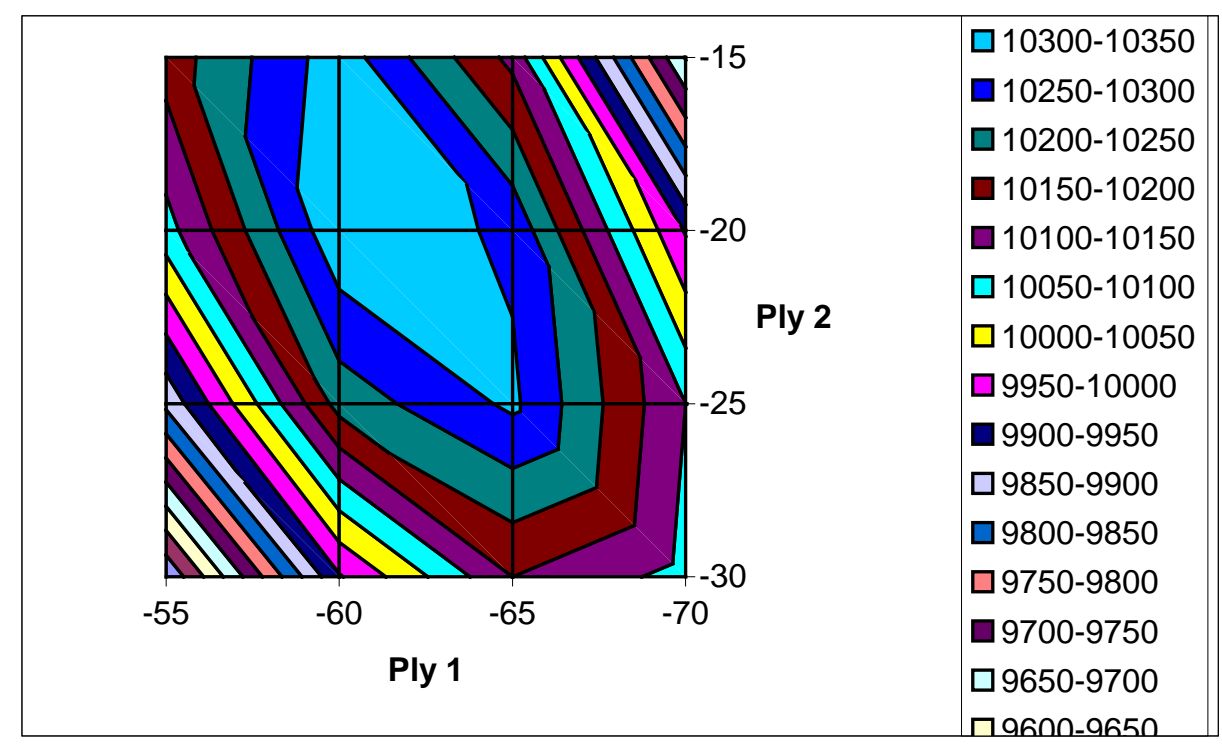

Aspect ratio 1.5
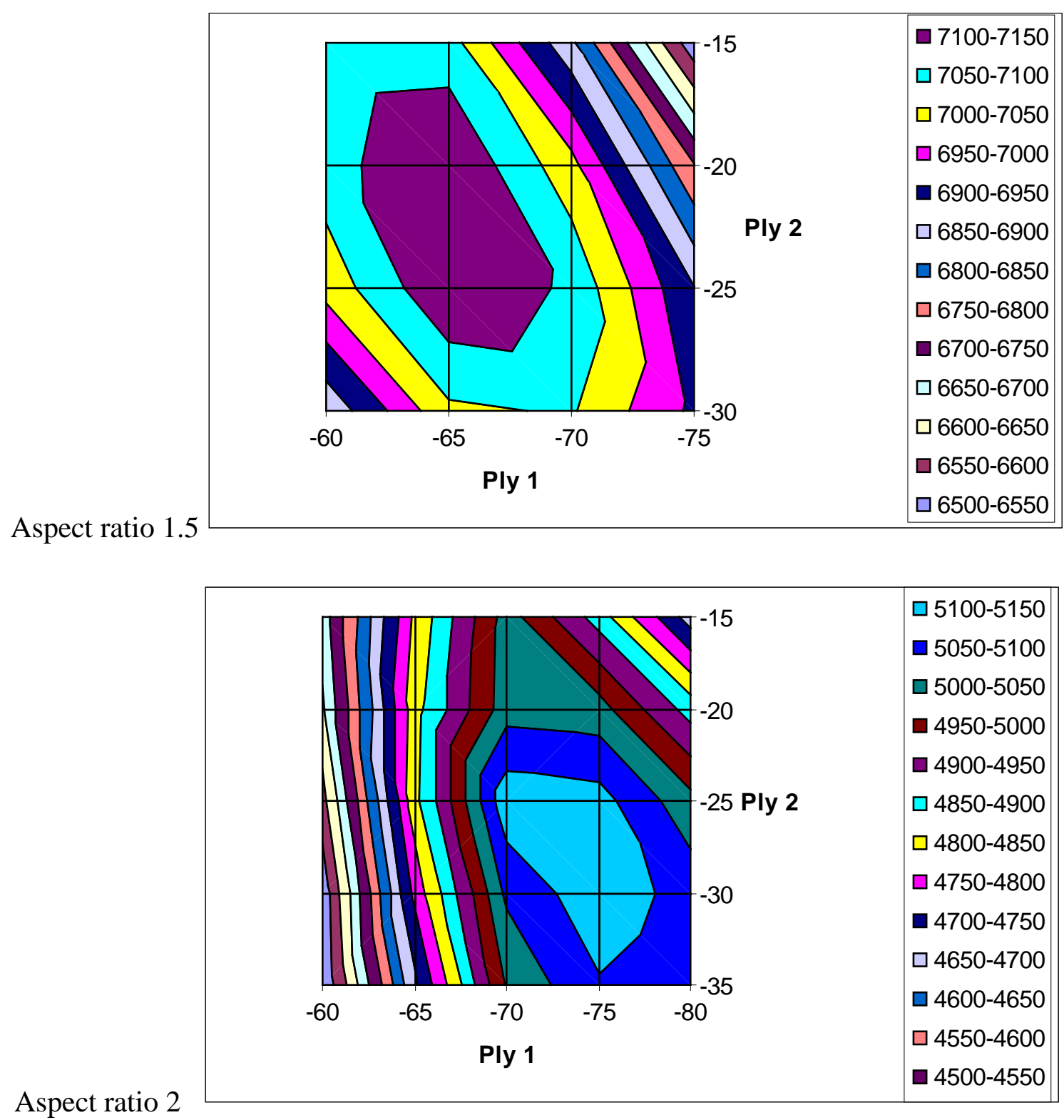

Figure 13 ABAQUS buckling load versus lay-up - radius of curvature R=100mm 
Aspect ratio 1

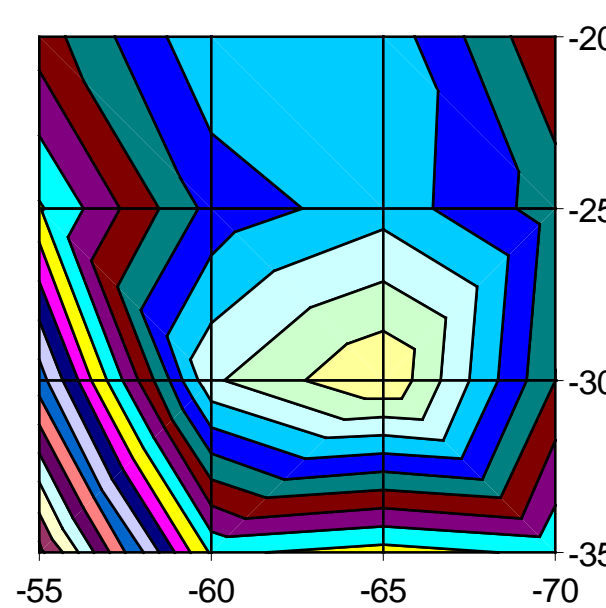

$\square 7100-7150$

口 7050-7100

口 7000-7050

口 6950-7000

— 6900-6950

Ply 2

6850-6900

- 6800-6850

- 6750-6800

6700-6750

口 6650-6700

6600-6650

Ply 1

- 6550-6600

6500-6550

Aspect ratio 1.5

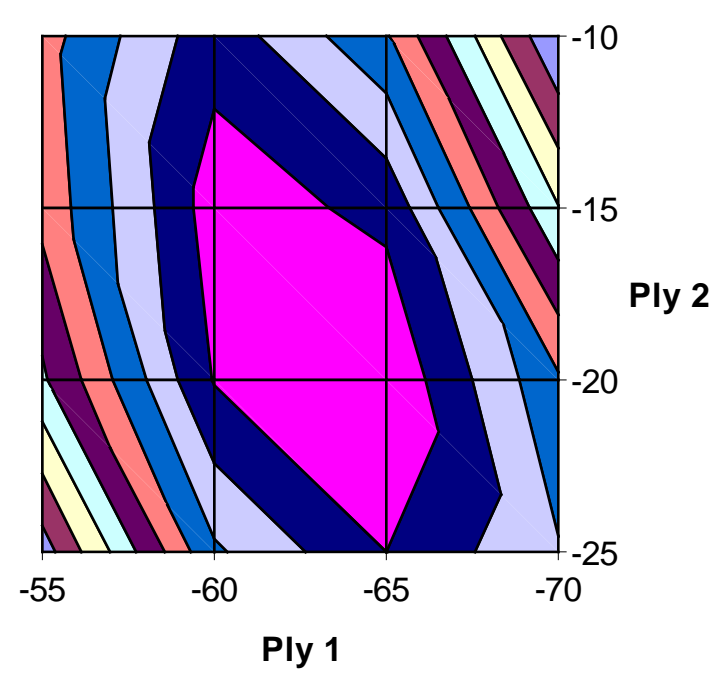

口 4825-4850

- 4800-4825

ㄴ 4775-4800

口 4750-4775

口 4725-4750

๑ 4700-4725

4675-4700

ㄴ 4650-4675

口 4625-4650

4600-4625

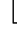

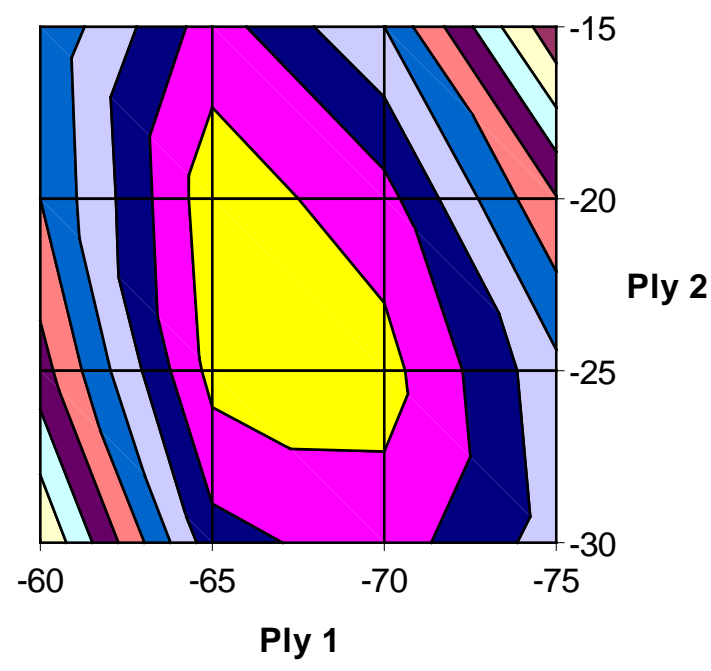

ㅁ 3800-3825

3775-3800

— 3750-3775

ㅁ 3725-3750

3700-3725

3675-3700

口 3650-3675

3625-3650

3600-3625

3575-3600

ㅁ 3550-3575

Aspect ratio 2

Figure 14 ABAQUS buckling load versus lay-up - radius of curvature R=177mm 

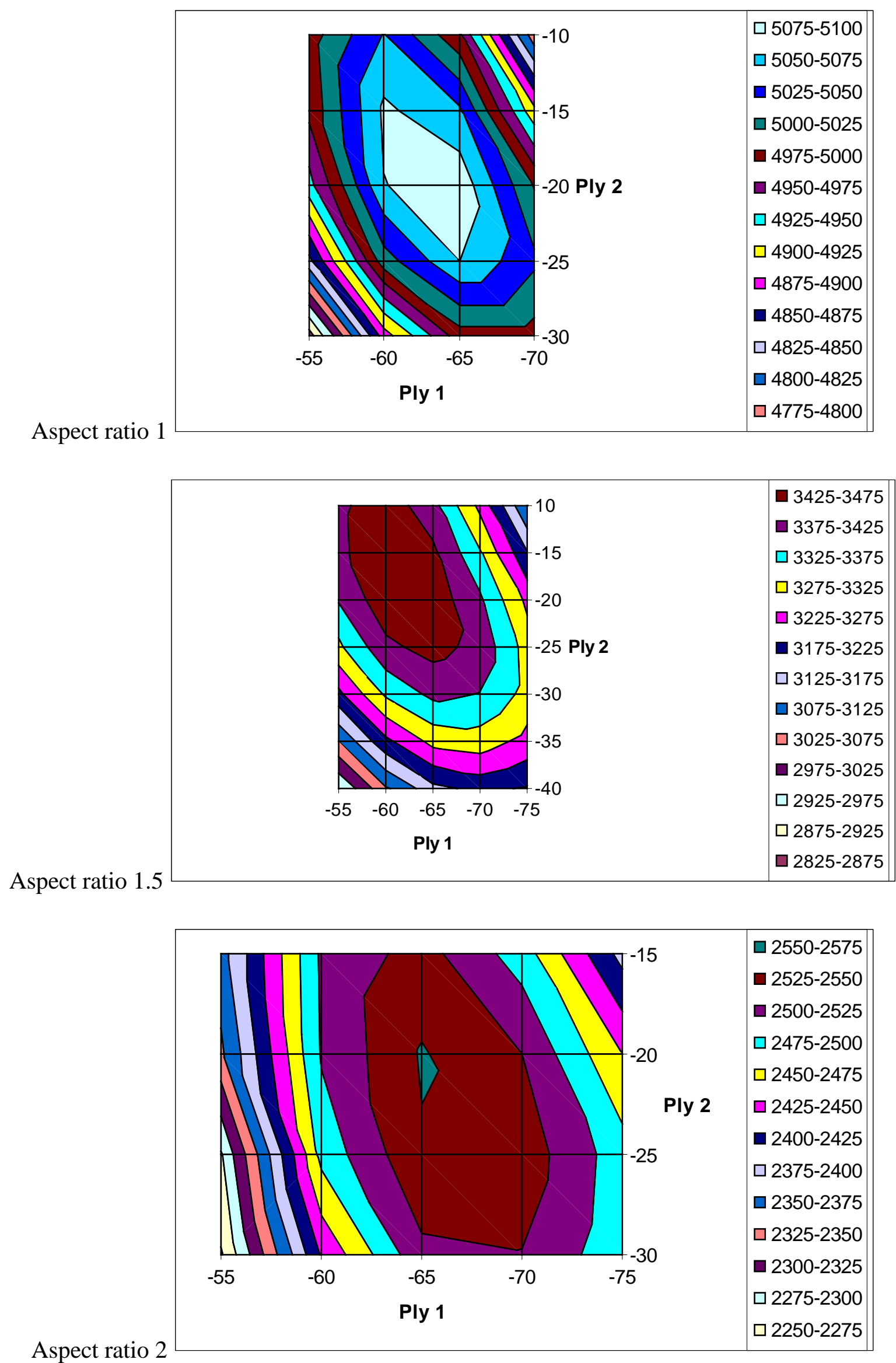

Figure 15 ABAQUS buckling load versus lay-up - radius of curvature R=322mm 


\section{Discussion}

The optimum lay-ups calculated using the two stage process involving multiple VICONOPT analyses in the first instance, followed by a much smaller number of finite elements analyses, are given in Table 3. These illustrate the success of the technique in determining complex optimum solutions to a problem that is insolvable using simple design equations. Study of Figures 13-15 illustrates a maximum of 35 finite element analyses, following an initial 1369 VICON analyses required to provide an optimum design. Thus the majority of the optimisation is carried out by the substantially quicker exact finite strip method, with the final result determined using the much slower, but more capable of modelling complex load and boundary conditions, finite element analysis, leading to a further increase in buckling load for the same thickness specimen of up to $13 \%$.

As anticipated, the optimum solutions align the external plies with the direction of the compressive stress due to the shear load in all cases. In terms of trends between radius of curvature, aspect ratio and optimum lay-up however there is little correlation, illustrating the complexity of the problem with many factors influencing the design. For panels with radius of curvature $\mathrm{R}=100 \mathrm{~mm}$ there is a link between optimum lay-up angle and aspect ratio, with the angle increasing with increased aspect ratio, as was found in flat plates. This is not supported by the other two sets of panels i.e. those with radius of curvature $\mathrm{R}=177$ and $322 \mathrm{~mm}$ where there is little variation in lay-up with changing aspect ratio. There is also some correlation between ply orientation and relative proportion of compressive stress with orientation angle decreasing as the relative proportion of compressive load increases. This can be illustrated by examining the difference between the VICON and FEA analyses. In the FEA (as in the experiment), the plates are built in at one end and a load is applied across the other introducing shear which varies across the plate and in-plane bending, which increases from zero at the point of load application, to a maximum at the built-in end. As noted earlier, 
it is not possible to model this varying in-plane bending in VICONOPT, since only longitudinally invariant loading can be introduced, so an average load representative of that found halfway along the plate was used. This results in the compressive load in the model being too great at the loaded end of the plate, and too low in the region near the built-in end where the plate buckles. Thus the effects of the compressive loading are underestimated in the most critical region resulting in optimum lay-ups with fibres aligned more towards the transverse direction, than would otherwise be the case. Study of the optimum lay-ups calculated by VICON and FEA show this to be the case, with the finite element results recommending a lay-up in which the fibres are more aligned with the $\theta=0^{\circ}$ direction. This trend is also in agreement with design guides such as Niu [7].

\section{Conclusions}

The results of the case studies presented illustrate the success of combining two techniques the exact finite strip analysis used in the software VICONOPT and the finite element method in this case using ABAQUS to optimize the lay-up of a series of geometries of plates and curved panels subject to complex load and boundary conditions. The method had been demonstrated to be extremely efficient, with the majority of the analyses necessary being performed using VICON which is particularly economical in terms of computational power and time, with the final stage in which much fewer analyses are needed, being performed in ABAQUS, which, whilst being capable of performing analyses on structures with much more complex load and boundary conditions is much slower. Whilst some automation of the process has been achieved by using 'change sets' to generate the input decks for the VICON studies, the analysis would clearly benefit from further or total automation including interfacing with the finite element package used. It would also be of great interest to extend the method to examine much more complex geometries such as for example an aircraft wing. 


\section{REFERENCES}

1. Anderson M S, Williams F W and Wright C J. Buckling and vibration of any prismatic assembly of shear and compression loaded anisotropic plates with an arbitrary supporting structure. International Journal of Mechanical Sciences 1983;25(8):585-596.

2. Wittrick W H and Williams F W. Buckling and vibration of anisotropic or isotropic plate assemblies under combined loading. International Journal of Mechanical Sciences 1974; 16(4):209-223.

3. Wittrick W $\mathrm{H}$ and Williams F W. An algorithm for computing critical buckling loads of elastic structures. Journal of Structural Mechanics 1973;1(4):497-518.

4. Anderson M S and Kennedy D. Transverse shear deformation in exact buckling and vibration analysis of composite plate assemblies. AIAA Journal 1993; 31(10):1963-1965.

5. Plank R J and Wittrick W H. Buckling under combined loading of thin, flat-walled structures by a complex finite strip method. Int. Journal for Numerical Methods in Engineering 1974;8(2): 323-339.

6. Wittrick W $\mathrm{H}$ and Williams F W. A general algorithm for computing natural frequencies of elastic structures. Quarterly Journal of Mechanics and Applied Mathematics 1971;24( 3): 263-284.

7. Niu M C Y. Composite airframe structures: practical design information and data. Hong Kong: Conmilit, 1992.

8. Jones R M. Mechanics of Composite Materials. Washington DC: Scripta, 1975.

9. Watson A, Kennedy D, Williams F W and Featherston C A. Buckling and vibration of stiffened panels or single plates with clamped ends. Advances in Structural Engineering 2003; 6(2):135-144

10. Chang R R, Chu K H and Kam T Y. Design of Laminated Composite Plates for Maximum Shear Loads. Transactions of ASME, Journal of Energy Resources Technology 1993; 115:314-322.

11. Tennyson R C, Buckling of Laminated Composite Cylinders: A Review, Composites, 1975; 17-24.

12. Leissa A W, Buckling of Laminated Composite Plates and Shell Panles, Report AFWAL-TR-85-3069, AF Wright Aeronautical Laboratories, 1985.

13. Kapania R K, A Review on the Analysis of Laminated Shells, ASME Journal of Pressure Vessel Technology 1989;11:88-96.

14. D.M. McGowan and M.S. Anderson, Development of curved plate elements for the exact buckling analysis of composite plate assemblies including transverse shear effects. 38th AIAA SDM Conference, AIAA-1997-1305, 1997. 